\title{
Anthropotechnical reliability in the reconstruction of the mobile environment of the means of mechanization and transportation
}

\author{
Vitaly Chulkov ${ }^{1, *}$ \\ ${ }^{1}$ Moscow State University of Civil Engineering, 26, Yaroslavskoye Shosse, 129337, Moscow, Russia
}

\begin{abstract}
An experimental and innovation study of the comfort level and organizational and anthropotechnical reliability of the mobile environment (panel trailer cabin, truck crane cabin and tower crane cabin) of the means of mechanization and transportation in construction was carried out using organizational and functional technology for express diagnostics of the comfort level of workers engaged in production activities in specific mobile environment during the working day.
\end{abstract}

\section{Introduction}

The study of means of mechanization and transportation (MMAT) that actually serve construction objects is conditionally divided into several successively carried out stages (blocks) [1]. The first block is the adaptation of well-known methods of parameterizing research objects to obtain values of the level of living comfort (LLC) and organizational and anthropotechnical reliability (OAR) of the mobile living environment of MMAT (panel trailer cabin, truck crane cabin and tower crane cabin) for specific operating conditions and specifics of activity.

Specialization is necessary, since different construction objects differ from each other in organizational and technological or organizational and managerial aspects. Even at the same construction site, various MMAT and their driver-operator workstations (mobile environments, ME) require different technical and organizational solutions to ensure safe and reliable parameterization of the worker's state in the process of express diagnostics using the gas-discharge visualization method (GDV).

The list of works on the specialization of methods and preparation of the study, without highlighting the exact sequence and significance of the work, includes:

- development of organizational technological management plans for field studies;

- formation of the composition and structure of the studied parameters;

- selection of intermediate diagnostic modes for parameter values ("surveys");

- technical modification of the equipment hardware;

- development of specialized software modules for the hardware-software complex;

- special planning of activities of the studied workers;

- preparation of research assistants and studied workers for conducting research in specific conditions.

\footnotetext{
*Corresponding author: aljurgaitis@gmail.com
} 
To search for potential and relevant errors in the organizational technical and management research plans, test field studies are carried out, the purpose of which is to develop a specific research methodology for the construction working process in imitation or in real-life conditions. In some cases, iterative repetition of the entire cycle of specialization of the methodology is required. The second block is field studies in which the psychophysiological state of specific workers is parameterized in a particular ME of the known MMAT to determine the qualitative characteristics of this ME. Comparability of the results and the possibility of taking into account the physical and chemical properties of the environment that affect the hardware are provided by additional surveys of the test object in each series of GDV-surveys.

The third block is to obtain conversion factors by surveys of test objects in order to adjust the obtained parameters of the state of workers in the process of their production activities and to compensate for the pathogenic effects of the environment on them in the MTE system.

To conduct the study, the GDV method was chosen, which has the considered above characteristics making it the most preferable for engineering studies of LLC and OAR in ME. The GDV method is based on a physical phenomenon known to science since the 17th century: the glow of objects of animate and inanimate nature in the field of a high-voltage gas discharge.

\section{Materials and methods}

Modern technical implementation of the method allows safe survey by bursts of pulses from 1/24 second to several minutes and a voltage in the discharge chamber from 16 to $25 \mathrm{kV}$. The time of surveying all 10 terminal phalanges of the fingers ranges from 3-5 to 15 minutes, depending on the survey mode [2-5].

Survey can also be carried out without the direct involvement of the operator (i.e. in semiautomatic mode), and data decryption can be performed at different times by different specialists. Portable equipment for conducting surveys is placed and operated during the study of LLC and OAR in a limited space of ME of a vehicle's cabin, crane, excavator or other MMAT, located in close proximity to the earth's surface or in a highly located and not always operatively accessible place (such as the cabin of a tower crane).

In the process of express diagnostics of LLC and OAR in ME, surveys were taken at workplaces in the cabin of a panel trailer driver, in the cabins of a truck crane driver, in the cabin of a tower crane operator.

Surveys were planned in time and space so that it was possible to compare the dynamics of LLC at two different workplaces during one work shift. For this, the time of survey for the panel trailer driver and the truck crane driver or the tower crane operator were coordinated.

The technological operations of the panel trailer driver's activity were identified:

- preparing the machine for access to the line;

- road to the loading point;

- loading (these first three operations within the working day of the panel trailer driver are repeated in a cycle, except for lunch time);

- road to the vehicle park at the end of the shift;

- car maintenance after a shift. The working day of the panel trailer driver is taken equal to 8 hours +1 hour for lunch.

The technological operations of a truck crane driver were also identified:

- driving on a road;

- loading, unloading and transport work at the construction site.

And finally, the technological operations of the tower crane operator were identified:

- preparation of the tower crane for work;

- loading, unloading and transport work at the construction site.

The shift working hours of the truck crane driver and the panel trailer driver is coordinated due to the adjustment of the technological process time of the truck crane driver to the panel trailer 
driver's schedule. The sequence of technological operations and the time intervals for their implementation are quite strictly regulated for the panel trailer. The work of the truck crane operator is more homogeneous and includes a large number of local finite elements (loading or unloading). Thus, a 5-minute break can be taken to conduct the GDV survey without any noticeable damage to the construction process. Longer breaks for conducting surveys (up to 15 minutes) can be made no more than 3 times a day. Based on this, a restriction was introduced on the number of GDV-survey modes in one session. The procedure for conducting a measurement session is unchanged and does not depend on the number of survey modes studied at one workplace of workers, etc. Emergencies are not excluded, depending on the specific circumstances of an organizational and technical nature.

The procedure for conducting a session of diagnostic measurements of LLC in ME was locally adjusted depending on the specific organizational conditions and capabilities of the technical execution of diagnostic procedures.

The standard cycle of the session of GDV surveys:

- input of the research assistant and the hardware-software complex into the working area;

- deployment of a hardware-software complex at the survey location and preparation for the survey;

- making a GDV-grams of the test object;

- making a GDV-grams of fingers of the employee's hands in the necessary modes;

- stowage of the hardware-software complex;

- withdrawal of the research assistant and the hardware-software complex from the working area.

Technical solutions provided by modern computer equipment have significantly reduced the startup time of the software part of the hardware-software complex.

In modern laptop computers running Windows 9x - XP operating systems, the Hibernate sleep mode is implemented - quick muting of the computer without unloading running drivers and programs with the ability to completely disconnect from external and internal power sources. A computer specially configured to use this mode is taken out of the muted state with a single press of the power key, and it is ready to work again with all initially launched programs and devices in less than one minute.

The GDV-camera device showed quite stable operation in the temperature range from $+5{ }^{\circ} \mathrm{C}$ to $+45^{\circ} \mathrm{C}$ and at an air humidity of not more than $85 \%$ with a period of time from connecting to the electric mains to the start of survey for about one minute.

The deployment time of the hardware-software complex (HSC) depends on the selected form of its storage and packaging. Working storage of HSC in assembled form is possible. With such storage, deployment takes 7-15 seconds. The total time of deployment and preparation of HSC for survey is slightly more than one minute.

With a small skill of the research assistant, tenfold shooting of the test object takes 10 seconds, and shooting of ten fingers in the first GDV mode with saving the results to the hard drive takes 1.5 - 3.5 minutes. The total preparation time for survey, shooting a test object and shooting the ten fingers of the operator's (driver's) hands in the first GDV mode with the subsequent stowage of HSC take no more than 5 minutes.

This is a perfectly acceptable survey time within the construction workflow. Up to three fiveminute surveys per hour are acceptable. For those MEs that allow the introduction of HSC and a research assistant to the workplace (cabin of a panel trailer or a truck crane), initial calculation data have been obtained that allow planning.

The cabin of a tower crane is a hard-to-get-at place. According to the work schedule, the tower crane operator leaves the workplace no more than two times per shift:

- for lunch break (if lunch cannot be delivered upstairs immediately at the start of the shift);

- at the end of the shift. The operator realizes breaks for natural needs, stipulated by the Labor Code, without leaving the cabin. For this, a technical hatch has been made in the cabin. Other persons must not come into the operator's cabin. 
Thus, it is possible to plan a survey of a tower crane operator in working conditions only if a hardware-software complex (HSC) is installed in the cabin in advance and is controlled remotely by a research assistant. In the case of managing HSC by the tower crane operator, unreliable data will be obtained, since the operator will be forced to switch to activities unusual for him, which will lead to additional stress and a strong distortion of the real values of LLC in ME.

When planning the study, it was assumed that with the introduction of express diagnostics of LLC and OAR, the operating environment of the panel trailer driver will change most sharply. It is he whose activities on the road and activities during loading and unloading operations differ significantly.

The difference between the activities of a tower crane operator and a truck crane operator during transport operations, loading and unloading operations is considered less distinguishable than a panel trailer driver, both in the nature of the activity itself and in the state of ME.

Based on the above assumptions, it was decided to "tie" the time of the sessions of the GDV studies to the technological operations of the panel trailer driver.

During the working day, three complete GDV studies were carried out in the three previously considered survey modes, and intermediate sessions of GDV studies were performed only in the first mode at the beginning of each technological operation (for example, before going on the road, before setting up for loading, before setting up for unloading, etc.).

Schedules of technological operations for a working day for the driver-operator of the truck crane and for the operator of the tower crane have been developed in such a way that it is possible to conduct measurement sessions simultaneously with the same measurement sessions in $\mathrm{ME}$ of the panel trailer driver.

For each examined employee, the total maximum number of sessions of GDV study per day did not exceed 19, and the time of survey was no more than $23 \%$ of the working day. The ssurvey, if possible, was carried out during the technological breaks of the main production activity.

An important aspect of conducting GDV study under construction conditions, in addition to the need to use the "GDV-camera - personal computer" complex, is the development of additional hardware for the uninterruptible power supply system of an autonomous HSC located in ME.

To conduct surveys, it is necessary to ensure:

- installation of HSC;

- power supply from AC $220 \mathrm{~V}$;

- control of HSC;

- a certain state of the terminal phalanges of the fingers of the subject under study.

The installation of HSC in the cabin of the panel trailer and in the cabins of the truck crane was carried out by the research assistant (in the most difficult cases, this was done by the main manager of the study). A special cover-table for the hardware-software complex is designed for:

- comfortable and safe installation of the complex in the driver's cabin ME,

- providing the ability to start the computer, the necessary programs and heating the GDV camera before placing HSC in the driver's cabin. No more than one minute passes from the beginning of the installation of equipment to the start of the survey, which ensures the reliability of the diagnosed parameters of the psychophysiological state of the examined person in ME.

The same cover-table serves as an additional electrical isolation of HSC from the cabin of a panel trailer or crane. Isolation provides safe research in the range of air humidity up to $95 \%$. The cover is designed for use at temperatures from $+10{ }^{\circ} \mathrm{C}$ to $+40^{\circ} \mathrm{C}$. Across much of Russia, this temperature regime is maintained from April to October. The use of HSC in the field in the autumnwinter period requires the development of a table-cover with a thermostatic system.

To provide power supply during the study of the characteristics of ME, depending on the circumstances, it is possible to use:

- operational power of technical tools, such as laptop computer batteries;

- operational power supplies of ME, additionally equipped with voltage converters;

- additional connection of a power network with voltage of 220 or $380 \mathrm{~V}$. 
In our case, a voltage converter MAC "Energy" 1.5 was used, connected to an operational power source of ME or to an additional battery considered together with the converter as part of HSC. The selected model made it possible to connect to the on-board power supply network of ME through a standard cigarette lighter socket, through a distribution panel or from a car battery with the voltage of 12-24 V, and ensured stable operation of the GDV-camera during a session of a complete GDV-study. With a standard power supply of $220 \mathrm{~V}$, the voltage converter MAC "Energy" allows charging a car battery with the voltage of 12 or $24 \mathrm{~V}$.

The power of the computer during the sessions of the GDV study was carried out from the rechargeable batteries of the mobile personal computer, which ensured the reliability of data safety and the complete independence of the computer voltage from the GDV camera device.

In the intervals between sessions, if necessary, the computer batteries were recharged from an alternating current network with a voltage of $220 \mathrm{~V}$ or from a car battery through a voltage converter MAC "Energy" 1.5.

In the cabins of a panel trailer and a truck crane, operational power supply of ME and, as necessary, a voltage converter MAC "Energy" 1.5 were used.

In the cabin of the tower crane, an additional battery and voltage converter MAC "Energy" 1.5 were used .

When conducting survey in the cabins of a panel trailer and a truck crane, HSC was controlled by a specially trained research assisstant. To ensure his working comfort and safety when conducting sessions of GDV studies in the cabins of MMAT, an easily installed seat was made to ensure that measurements are taken and the research assistant is protected from falling outside the cabin. Due to the small size of the truck crane cabin, a special research assistant seat was installed in the doorway of the truck crane cabin and fastened by latches to pre-mounted holders [6].

The research assistant was additionally insured against falling by a standard safety kit - a safety belt and a steel safety cable, which were fastened to the cabin and to the research assistant's safety belt. The safety cable has a polyvinylchloride electrical plastic insulation. The computer and the GDV camera were powered from the battery through the voltage converter MAC "Energy" 1.5.

Theresearch assistant cannot access the tower crane cabin, therefore, HSC was installed in this cabin so that the display of the additional laptop was closed. Special network software was used that allows controlling the computer terminal of HSC in the cabin of a tower crane from a server installed remotely and connected to the terminal.

The computers were connected using the Ethernet $100 \mathrm{MB}$ network protocol, which organizes the control of the client computer of HSC and two-way audio communication between computers at distances of up to 50-100 $\mathrm{m}$ without the high cost of additional equipment. To conduct the survey without the direct participation of the research assistant, the equipment for controlling the GDV camera was modified. Normally, the GDV camera is controlled by a modified mouse manipulator, which is used as:

- frame pointer in the GDV-capture program;

- button to start shooting a frame;

- gas pulse triggering console in the GDV camera.

For shooting in the cabin of a tower crane, a manipulator pedal has been made that plays the role of:

- remote control for launching gas discharge pulses in the GDV camera;

- start button of shooting the frame.

The research assistant conducts the frame indication remotely from the server, coordinating his actions with the crane operator through audio communication. The computer in the cabin switches from sleep mode to work mode on the command of a server controlled by the research assistant. After that, the crane operator turns on the voltage converter, then the GDV camera and prepares for shooting. Shooting begins one minute after turning on the GDV camera. After shooting, the crane operator turns off the GDV camera and voltage converter, and the research assistant puts the computer installed in the cabin of the tower crane into a muted state. 
To ensure the standard characteristics of the measurement procedures and reduce the degree of dirtying the skin of the terminal phalanges of the fingers of a panel trailer driver, a truck crane driver-operator and a tower crane operator, they were offered a special glycerin solution for treating the skin of the hands, and it was necessary to work with special cotton working gloves. In the initial phase of the study, this caused bewilderment and humorous attitude of workers who are accustomed to working at a construction site without gloves and do not attach importance to hand dirtying during labor.

A minute before the start of the study, the terminal phalanges of the fingers were wiped with a squeezed sponge dipped in a glycerin solution, and then dried with a sanitary napkin.

The field study consists of two parts:

- tenfold shooting of the test object to ensure comparability of the results of the study in different environments or in the same ME at different times;

- parameterization of the state of organs and systems of the human body by GDV method.

In the vast majority of cases, the psychophysical characteristics of the state of the organism change most rapidly in the process of activity. Therefore, it makes sense to make GDV-grams in the first mode more often than once per hour.

GDV survey is an additional load of electromagnetic fields and radiation on the human body. Standards for the permissible number of GDV studies have not yet been introduced.

Ten years of experience in GDV studies of various specialists around the world shows that it is desirable to carry out a complete GDV study using all three survey modes without damage to health up to six times a day.

GDV studies using only the first mode can be performed without damage to health up to three times per hour.

\section{Results and discussion}

Assessment of the permissible load shows that the maximum number of GDV-studies almost does not allow carrying out the main production activity qualitatively. GDV-survey can be considered as a workload during a working day. Therefore, the plan of sessions of GDV studies during the working day was drawn up on the basis of the requirements of the work process and the possibility of introducing an additional work load into the work schedule without harming the health and working process.

By agreement with the tested workers and planning services, which provided the process of building production at the facility, the standard for the expenditure of time for the employee to conduct research during the working day was adopted:

- no more than $25 \%$ of the total working time, including breaks;

- no more than $60 \%$ of break time;

- the working day, taking into account all the breaks, cannot be increased by more than $10 \%$.

Based on this standard, graphs of sessions of GDV studies for the panel trailer driver, truck crane driver-operator and tower crane operator were built (table 1).

According to the data in Table 1, graphs of changes in the LLC values are constructed over the course of a working day of the panel trailer driver and the tower crane operator during their joint work at the construction site (Fig. 1).

The corridor of changes in the LLC values from 0.75 to 0.82 . At the beginning of work, LLC is 0.75 and rises to $0.79-0.81$ only by the middle of the working day. To enable comparison of the results of studies of different ME, examination schedules for all subjects under the study were "tied" to the work schedule of the panel trailer driver. 
Table 1. Truck crane driver-operator and tower crane operator.

\begin{tabular}{|c|c|c|c|c|c|c|}
\hline No. & $\begin{array}{l}\text { Start of } \\
\text { a } \\
\text { session }\end{array}$ & $\begin{array}{l}\text { Session } \\
\text { time }\end{array}$ & $\begin{array}{l}\text { Stage of work of a } \\
\text { panel trailer driver }\end{array}$ & $\begin{array}{l}\text { LLC } \\
\text { value }\end{array}$ & $\begin{array}{l}\text { Stage of work of a } \\
\text { tower crane operator }\end{array}$ & $\begin{array}{l}\text { LLC } \\
\text { value }\end{array}$ \\
\hline 1 & 08.00 & 0.15 & Start of a working day & 0.754 & Start of a working day & 0.758 \\
\hline 2 & 08.45 & 0.05 & Start of loading & 0.782 & $\begin{array}{l}\text { Inspection of a crane, } \\
\text { tracks, devices and } \\
\text { containers }\end{array}$ & 0.776 \\
\hline 3 & 09.15 & 0.05 & End of loading & 0.804 & $\begin{array}{l}\text { Lifting in the crane } \\
\text { cabin, clearing the site } \\
\text { of cargo }\end{array}$ & 0.792 \\
\hline 4 & 09.40 & 0.05 & Start of unloading & 0.797 & $\begin{array}{l}\text { Unloading of a panel } \\
\text { trailer }\end{array}$ & 0.790 \\
\hline 5 & 10.10 & 0.05 & End of unloading & 0.812 & $\begin{array}{l}\text { Loading and unloading } \\
\text { works (LUW) on the } \\
\text { construction site }\end{array}$ & 0.794 \\
\hline 6 & 10.35 & 0.05 & Start of loading & 0.801 & $\begin{array}{l}\text { LUW on the } \\
\text { construction site }\end{array}$ & 0.786 \\
\hline 7 & 11.05 & 0.05 & End of loading & 0.807 & $\begin{array}{c}\text { LUW on the } \\
\text { construction site }\end{array}$ & 0.788 \\
\hline 8 & 11.30 & 0.05 & End of unloading & 0.765 & $\begin{array}{c}\text { Unloading of a panel } \\
\text { trailer }\end{array}$ & 0.752 \\
\hline 9 & 12.00 & 0.15 & Start of a lunch break & 0.798 & Start of a lunch break & 0.783 \\
\hline 10 & 13.00 & 0.05 & End of a lunch break & 0.781 & End of a lunch break & 0.776 \\
\hline 11 & 13.30 & 0.05 & Start of loading & 0.787 & $\begin{array}{l}\text { LUW on the } \\
\text { construction site }\end{array}$ & 0.780 \\
\hline 12 & 13.55 & 0.05 & End of loading & 0.779 & $\begin{array}{c}\text { LUW on the } \\
\text { construction site }\end{array}$ & 0.778 \\
\hline 13 & 14.25 & 0.05 & Start of unloading & 0.784 & $\begin{array}{c}\text { Unloading of a panel } \\
\text { trailer }\end{array}$ & 0.781 \\
\hline 14 & 14.50 & 0.05 & End of unloading & 0.770 & $\begin{array}{l}\text { LUW on the } \\
\text { construction site }\end{array}$ & 0.778 \\
\hline 15 & 15.20 & 0.05 & Start of loading & 0.773 & $\begin{array}{l}\text { LUW on the } \\
\text { construction site }\end{array}$ & 0.772 \\
\hline 16 & 15.45 & 0.05 & End of loading & 0,766 & $\begin{array}{c}\text { LUW on the } \\
\text { construction site }\end{array}$ & 0.765 \\
\hline 17 & 16.15 & 0.05 & Start of unloading & 0.755 & $\begin{array}{c}\text { Unloading of a panel } \\
\text { trailer }\end{array}$ & 0.760 \\
\hline 18 & 16.40 & 0.05 & End of unloading & 0.755 & $\begin{array}{l}\text { LUW on the } \\
\text { construction site }\end{array}$ & 0.752 \\
\hline 19 & 17.30 & 0.15 & $\begin{array}{l}\text { Marking the waybill, } \\
\text { road to the vehicle } \\
\text { park, parking, end of } \\
\text { a working day }\end{array}$ & 0.750 & $\begin{array}{l}\text { Crane in the parking } \\
\text { zone, descent, crane on } \\
\text { the brakes, inspection, } \\
\text { note in the logbook }\end{array}$ & 0.748 \\
\hline
\end{tabular}


LLC value

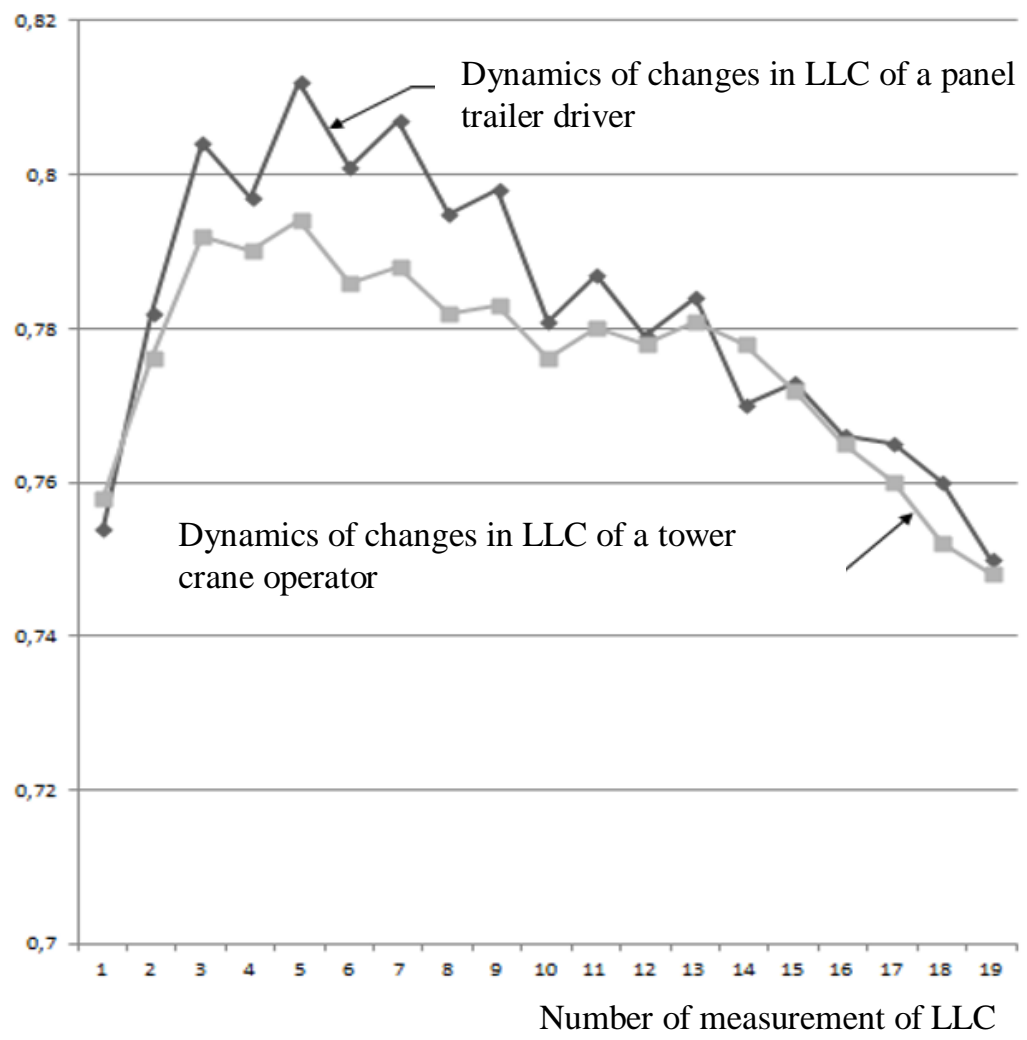

Fig. 1. Fluctuations of LLC during the working day of the panel trailer driver and the tower crane operator in the process of their joint work, (2003, [1]).

The work schedules of the driver-operator of the truck crane and the tower crane operator took into account special technological breaks for conducting sessions of GDV studies.

Before carrying out the studies, the research assistant and the subjects (panel trailer driver, truck crane driver-operator and tower crane operator) underwent special training: safety training, courses on the use of the GDV camera, courses on the use of computer and electric tools, which are part of HSC [1].

The database and descriptions of the conducted studies include: ME;

- GDV-grams of test objects with the date and exact time of diagnostics of LLC in a specific

- GDV-grams of the terminal phalanges of the fingers with indication of the details of the object (finger), date and exact time of survey, as well as of the studied ME;

- description of weather and environmental conditions at the location of the survey (temperature, air humidity, atmospheric pressure, etc.);

- comments and subjective assessment of the health status of the diagnosed person (in free form);

- protocol of diagnostic research;

- protocol of disagreement with the plan of production activities (recording the failures in the technology of the main building production, which happened due to the express diagnostics of LLC in $\mathrm{ME}$ ). 


\section{Conclusion}

To collect, store and process the results, a software package and automation tools based on the MS Office 97 system have been developed.

Some types of production activities increase LLC, while other production processes lower it. By the end of the working day, LLC is reduced to 0.74: general fatigue as a result of labor activity is manifested.

For a tower crane operator, the spread of LLC values during operation is less than for a panel trailer driver, since the environment of the activity carried out by the operator is more uniform. The difference in the LLC values at the beginning and at the end of the working day for the tower crane operator is greater, since the number of production processes that restore LLC (recreational) for him is less than that of the panel trailer driver.

Changes in the environment and nature of the activity have a recreational effect on the panel trailer driver, which allows him to maintain a higher level of LLC by the end of the working day.

Alternating recreational activities for a panel trailer driver are loading and unloading panels at the warehouse areas of a reinforced concrete plant and in the loading and unloading area of a construction site, as well as driving a long vehicle in urban conditions.

\section{References}

1. V.O. Chulkov, Life safety. Organizational and anthropotechnical reliability of functional systems of the mobile environment of construction production. Series "Infographic fundamentals of functional systems" (IFFS) ( ASV Publishing House, Moscow, 2003)

2. K.V. Sudakov, Normal physiology. The course of physiology of functional systems (Medical News Agency, Moscow, 1999)

3. R.V. Rotenberg, Fundamentals of the reliability of the driver-car-road-environment system (Mashinostroenie, Moscow, 1986)

4. K.V. Sudakov, Sanatron. The system of assessment and rehabilitation of early violations of the physiological functions of a person in real life conditions (Gorizont, Moscow, 2001)

5. P.N. Smirnov, Computer-aided design of technology for diagnosing the quality of the mobile living environment in construction (INO, Moscow, 2002)

6. V.O. Chulkov, I.Ya. Masturov, Integrated anthropotechnical engineering methodology for instrument and analytical diagnostics and compensation of the level of human comfort in the environment (Central Research, Design and Experimental Institute of Organization of Mechanization and Technical Assistance for Construction, Laboratory of Information Technologies, Economics and Life Safety, Moscow, 2002)

7. P. Oleinik, A. Yurgaytis, MATEC Web of Conferences 117, 00130 (2017) https://doi.org/10.1051/matecconf/201711700130

8. D. Topchiy, A. Shatrova, A. Yurgaytis, MATEC Web of Conferences 193, 05032 (2018) https://doi.org/10.1051/matecconf/201819305032

9. P. Oleinik, A. Yurgaytis, MATEC Web of Conferences 193, 05010 (2018) https://doi.org/10.1051/matecconf/201819305010

10. M. Rogalska, W. Bozejko, Z. Hejducki, Automation in Construction 18, 24-31 (2008) doi:10.1016/j.autcon.2008.04.002

11. W. Bozejko, Z. Hejducki, M. Uchroński, M. Wodecki, Journal of Civil Engineering and Management 20 (2014) DOI: 10.3846/13923730.2014.906496

12. W. Bozejko, Z. Hejducki, M. Wodecki, Journal of Civil Engineering and Management 18(5), 621-630 (2012) 